\title{
SASKATCHEWAN CHRISTMAS MAMMAL COUNT - 1982
}

Compiled by WAYNE C. HARRIS, Box 414, Raymore, Saskatchewan. SOA 3J0

A total of 49 counts were received this year reporting 28 species during the count period. The number of counts exceeds the previous high of 45 in 1980 while the number of species equals the previous high reported in 1978 and 1980. General light snow cover combined with very mild temperatures throughout the count period are undoubtedly the reason for the increase in counts.

Two new species were reported this year. A Flying Squirrel was seen at Waskesiu in Prince Albert National Park and at Good Spirit Lake, Bill and Joyce Anaka found fresh Northern Pocket Gopher diggings.

Rabbit populations appear to be down with both frequency and overall numbers less than last year for Whitetailed Jack Rabbit and especially Snowshoe Hare. Coyote populations are up as are White-tailed Deer. Mild weather is undoubtedly responsible for the increased activity of such species as Striped Skunk and Badger. A new mammal detection device was initiated this year by Alan Smith when he used an extra sensory perceptive nose to locate a Striped Skunk on the Elbow count!

The only species which was expected but not reported was the Lynx. With Snowshoe Hare numbers declining in the forest the Lynx usually becomes more mobile and is recorded in the southern portions of the province maybe next year.

For weather, coverage and participants on these counts please refer to the Christmas Bird Counts found elsewhere in this issue. Symbols found in the table are as follows:

* Identified by tracks with estimated number of individuals in parentheses.

+ Seen during count period but not on count day.

$L$ Active lodges seen with number in parentheses.

$\mathrm{H}$ Species heard but not seen with number in parentheses.

$S$ Presence indicated by smell with number in parentheses.

D Fresh diggings located.

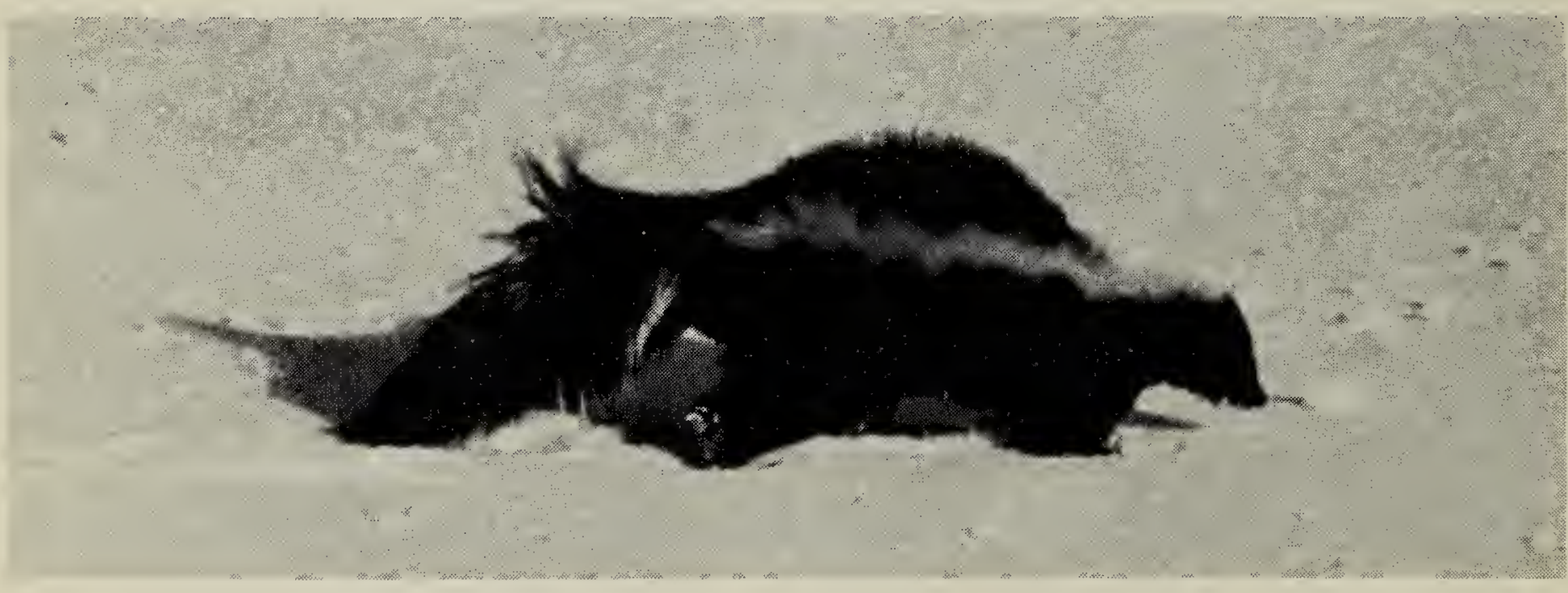




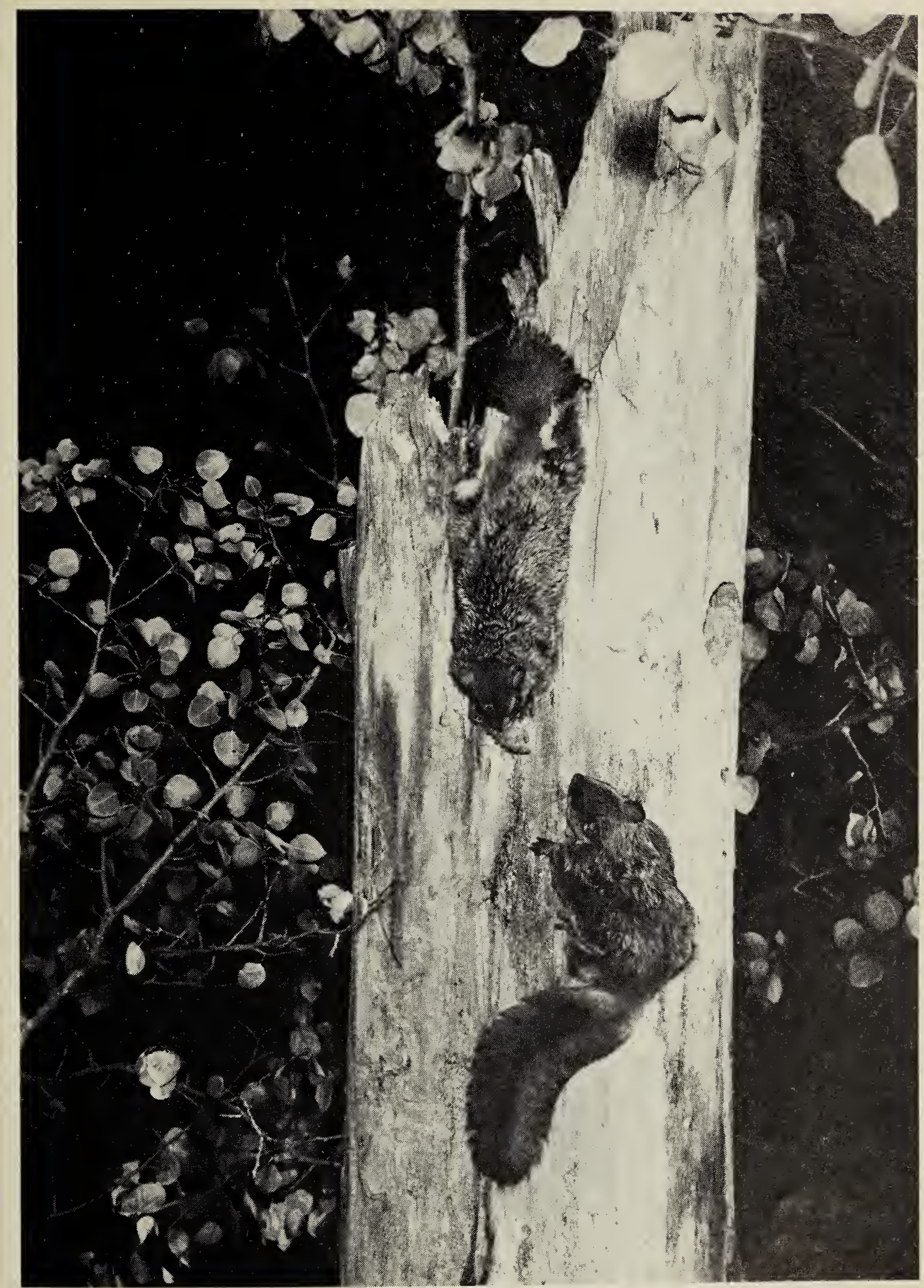

Northern Flying Squirrels

Hans Dommasch 
Table 1-1. SASKATCHEWAN CHRISTMAS MAMMAL COUNT.

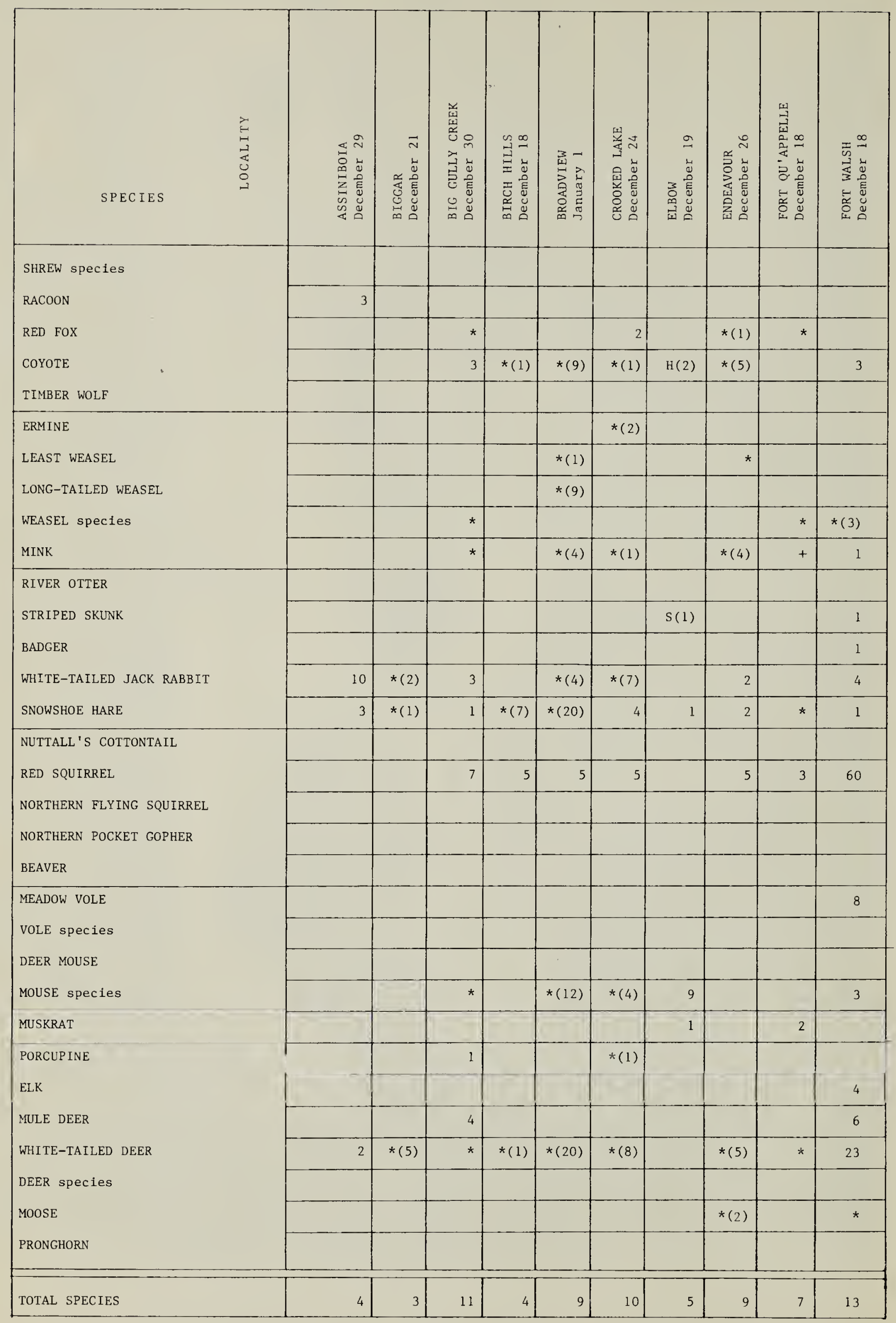


Table 1-2. SASKATCHEWAN CHRISTMAS MAMMAL COUNT.

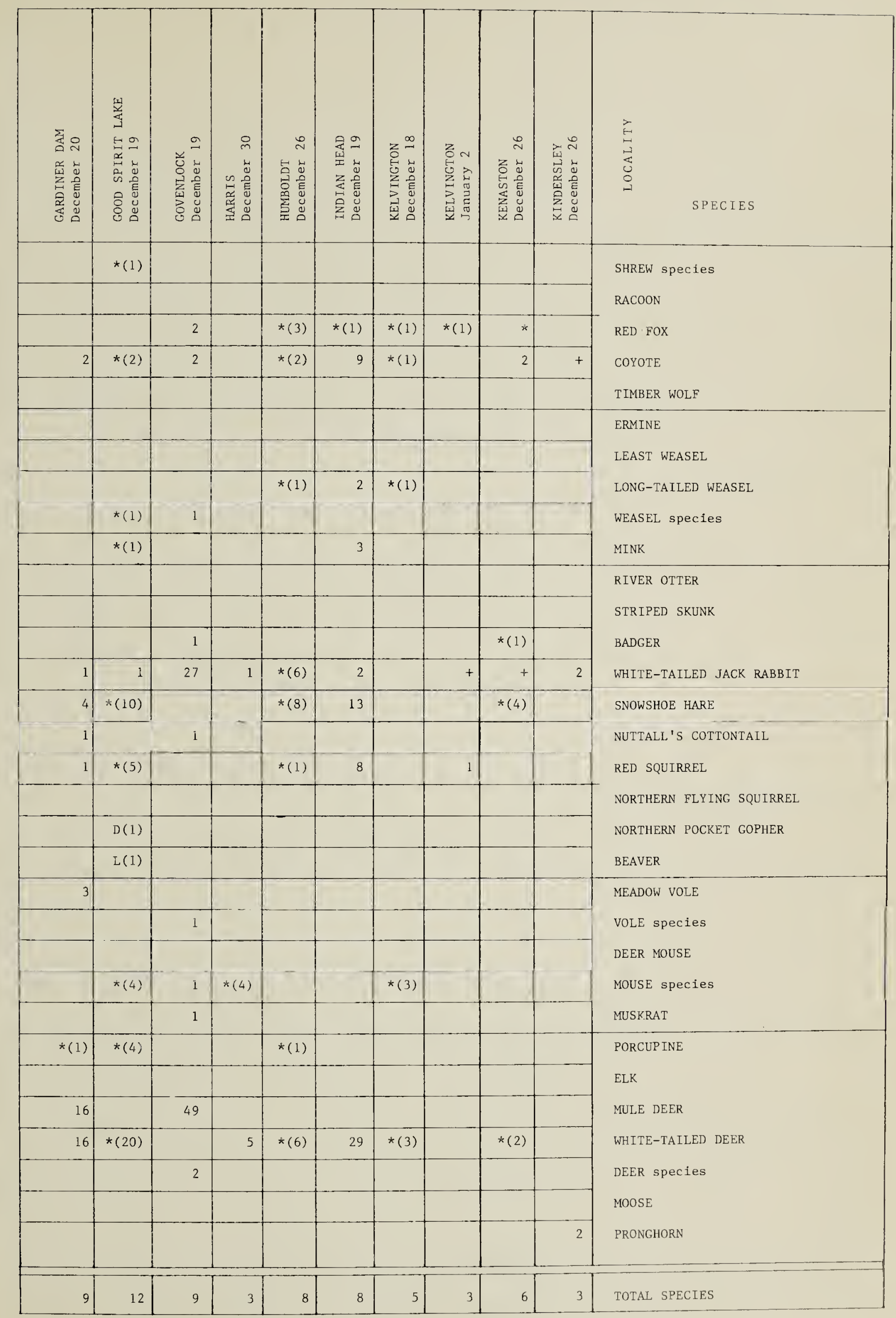


Table 1-3. SASKATCHEWAN CHRISTMAS MAMMAL COUNT.

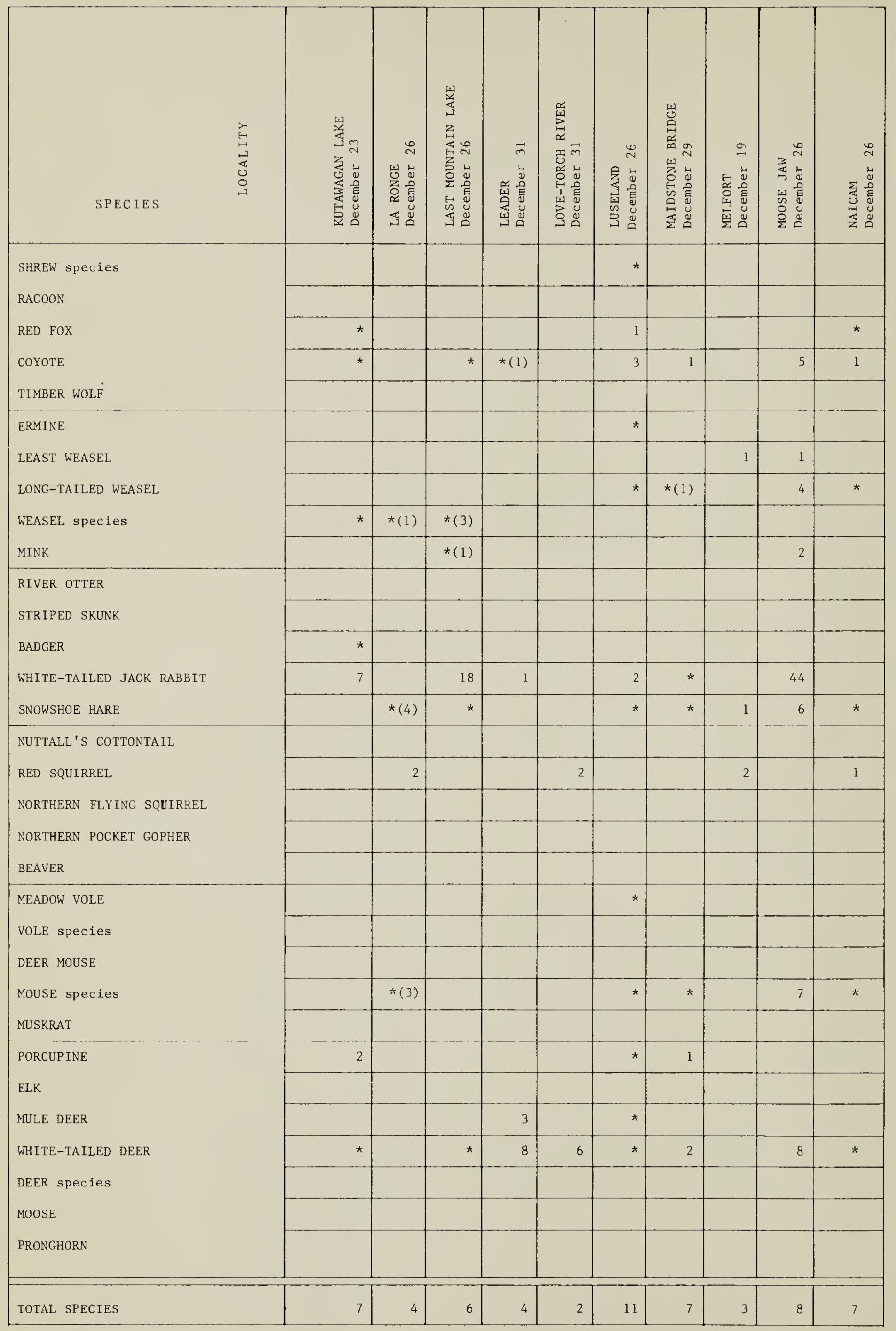


Table 1-4. SASKATCHEWAN CHRISTMAS MAMMAL COUNT.

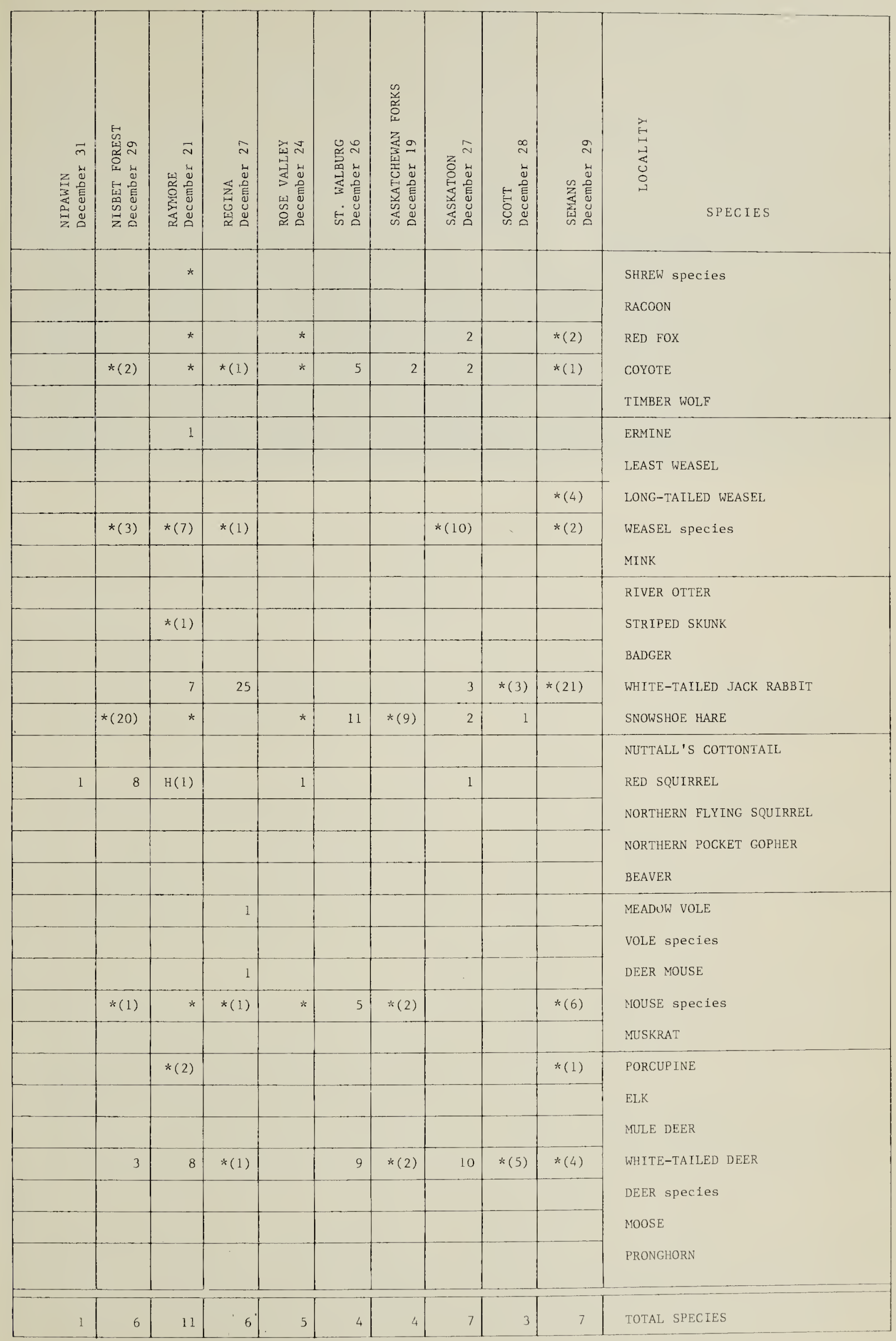




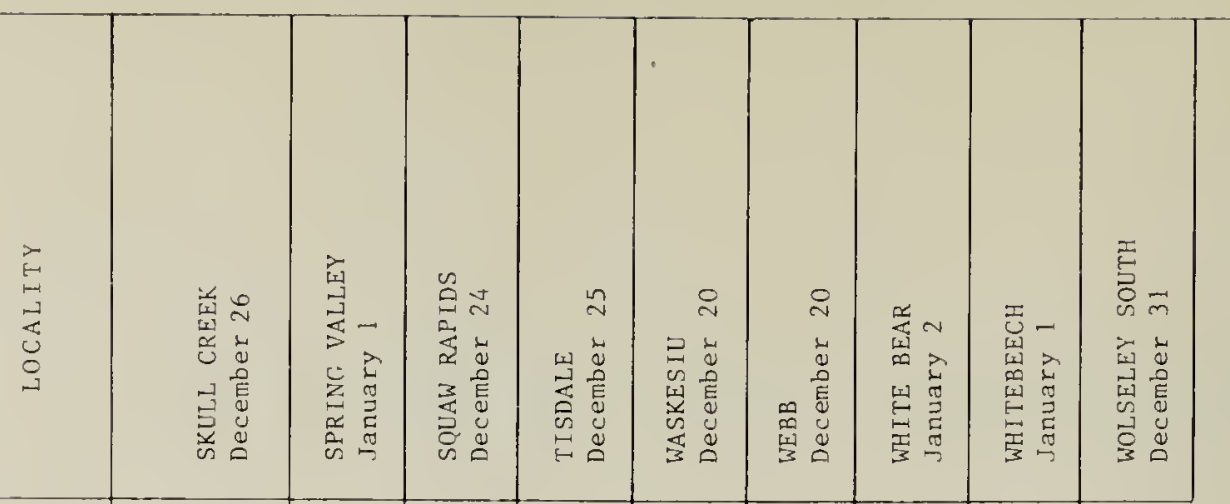

SHREW species

RACOON

RED FOX

COYOTE

TIMBER WOLF

ERMINE

LEAST WEASEL

LONG-TAILED WEASEI

WEASEL species

MINK

RIVER OTTER

STRIPED SKUNK

BADGER

WHITE-TAILED JACK RABBIT

SNOWSHOE HARE

NUTTALL'S COTTONTAIL

RED SQUIRREL

NORTHERN FLYING SQUIRREL

NORTHERN POCKET GOPHER

BEAVER

MEADOW VOLE

VOLE species

DEER MOUSE

MOUSE species

MUSKRAT

PORCUPINE

ELK

MULE DEER

WHITE-TAILED DEER

DEER species

MOOSE

PRONGHORN

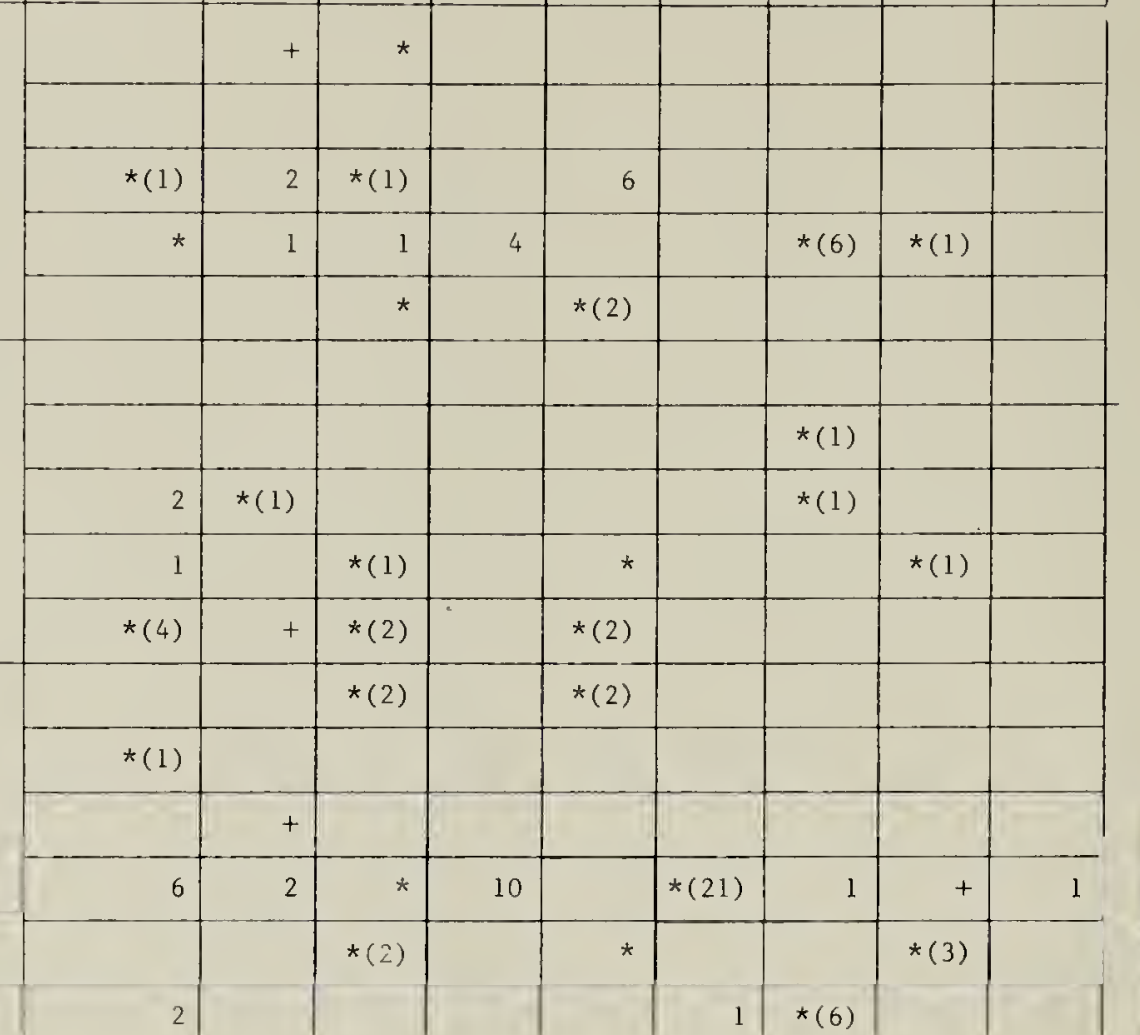

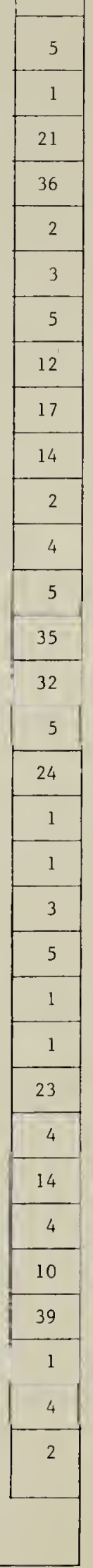

TOTAL SPECIES

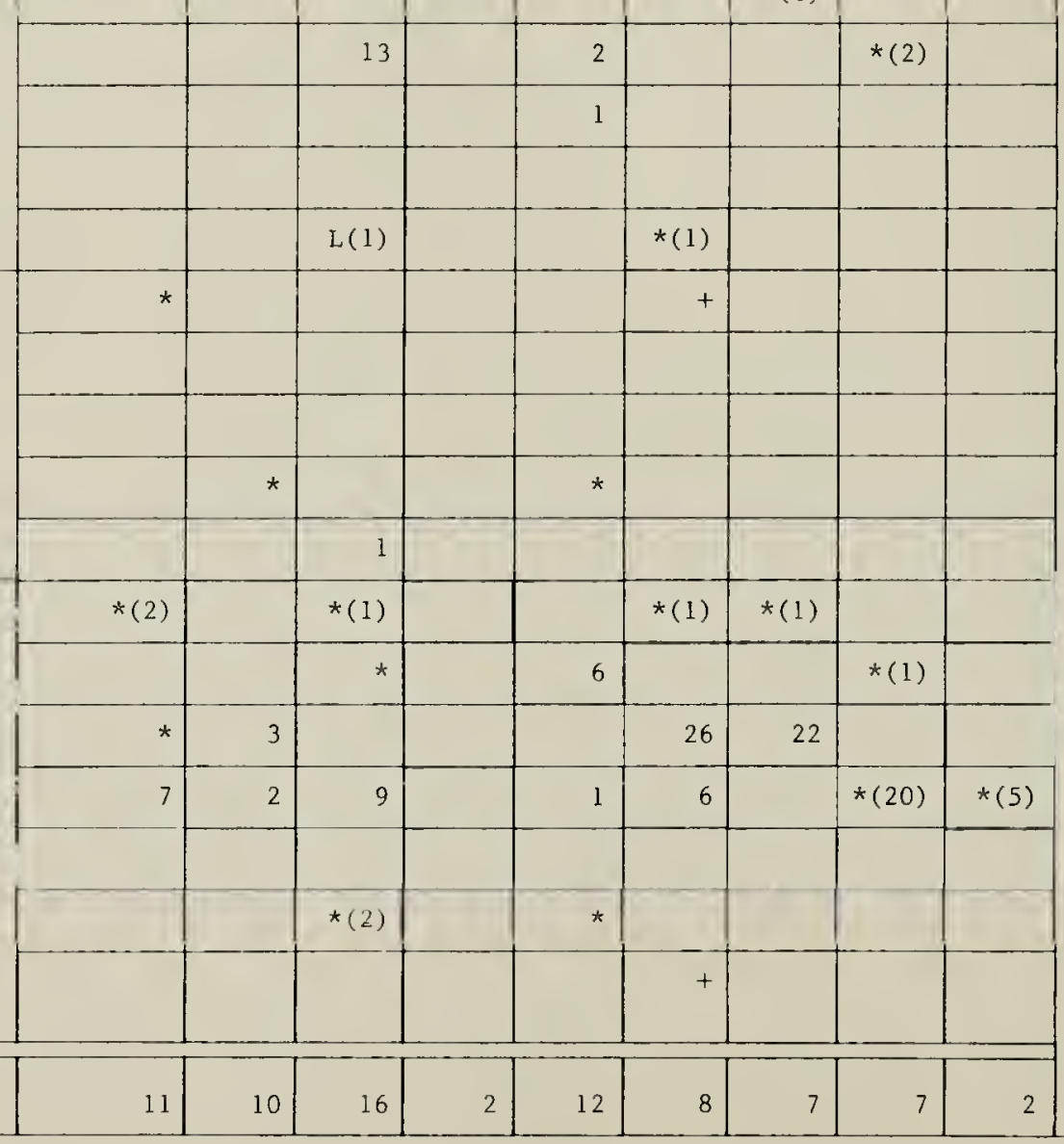

